\title{
PHOTOELECTRIC STUDY OF SOME FACTORS RELATED TO BLOOD CLOTTING
}

\author{
By H. F. DEUTSCH \\ (From the Departments of Physical and Physiological Chemistry, University of \\ Wisconsin, Madison)
}

(Received for publication June 4, 1945)

The determination of the thrombic or prothrombic activity of blood or blood plasma preparations is beset with many difficulties. The use of a variety of methods and means of expressions of thrombin units has served to complicate rather than clarify the basic aspects of this problem. The application of existing assay methods to new prothrombin-containing systems likewise presents new problems. The work reported here represents a study of some of the factors affecting the assay of prothrombin in protein components of human plasma which has been fractionated by the low temperature-ethanol procedures of Cohn et al. (1). It was of particular interest to study the influence of different fractions derived from a parent substance on the "two-stage" assay method of Warner, Brinkhous and Smith (2) in which all of the prothrombin is converted to thrombin prior to its addition to a system containing fibrinogen.

In conjunction with this work, a photoelectric determination of the clotting time was developed and utilized.

\section{EXPERIMENTAL}

The prothrombin-rich material utilized in this work was the human blood plasma fraction II + III of Cohn et al. (1). The thrombin determinations were made by the "two-stage" method of Warner, Brinkhous and Smith (2). Activation of prothrombin to thrombin was carried out in a system of approximately 0.15 ionic strength and a final volume of $2.0 \mathrm{ml}$. using either rabbit brain (3) or human placental thromboplastin (4) as the activator. The molarity of $\mathrm{Ca}$ ions was approximately 0.025. The activity of the thrombin was measured by determining the time necessary for $0.1 \mathrm{ml}$. of this solution to clot $1.0 \mathrm{ml}$. of a 0.3 per cent solution of fibrinogen 1 at $25^{\circ} \mathrm{C} .\left( \pm 1^{\circ}\right)$. The thrombin was diluted sufficiently so as to give a clotting time (in the neighborhood) of 45 seconds, which has been designated as one unit in this work.

\footnotetext{
1 The fibrinogen was part of a sample prepared by the Department of Physical Chemistry, Harvard Medical School from the so-called Fraction I (1).
}

\section{PHOTOELECTRIC METHOD FOR DETERMINATION OF CLOTTING TIME}

The appearance of a clot or of the formation of fibrils of fibrin after addition of thrombin to a fibrinogen solution was observed visually in preliminary experiments. The fibrinogen solution was agitated by tilting the reaction tube back and forth. This method, while commonly used, is tedious and does not lend itself to ready duplication.

It was noted that the conversion of fibrinogen to fibrin was coincident with the development of a marked turbidity. This development of turbidity could be followed photoelectrically, and it was found that this increase in light absorption by the fibrinogen solution could be correlated with the clotting time. Investigation of the various conditions relating to the light absorption technique for the determination of the clotting of fibrinogen solutions was carried out by using the following procedure. One $\mathrm{ml}$. of fibrinogen solution was placed in each of a series of matched $10 \times 60 \mathrm{~mm}$. glass tubes. The tube was placed in a solid holder having a narrow vertical slit which allowed light to pass through the solution to the photocell of a Coleman Spectrophotometer. After the light intensity had been adjusted to give a galvanometer reading of $100,0.1 \mathrm{ml}$. of a thrombin-containing solution was forcefully blown into the fibrinogen solution by means of a $0.1 \mathrm{ml}$. pipette. To insure uniform mixing, the material was drawn up into the pipette and forcefully returned. The galvanometer reading was then readjusted to 100 if there had been any deviation, and observations of the increase in light absorption versus time were recorded by means of a stopwatch from the time of thrombin addition to the fibrinogen solution. The time necessary for the thrombin delivery and necessary galvanometer readjustment requires approximately 5 to 8 seconds. In the systems under study, little light absorption was noted within the first 15 to 20 seconds since thrombin concentrations were adjusted to give clots in the range of 30 to 60 seconds. A typical absorption curve under the above conditions is shown in Figure 1. Using this technique, various conditions affecting this system were studied. It can be seen from Figure 2 that the increase in light absorption during clotting was greater at the shorter wave lengths. When using light of a constant wave length and identical amounts of thrombin, it was noted that a decrease of the fibrinogen concentration resulted in a lowered rate of light absorption. As shown by Figure 


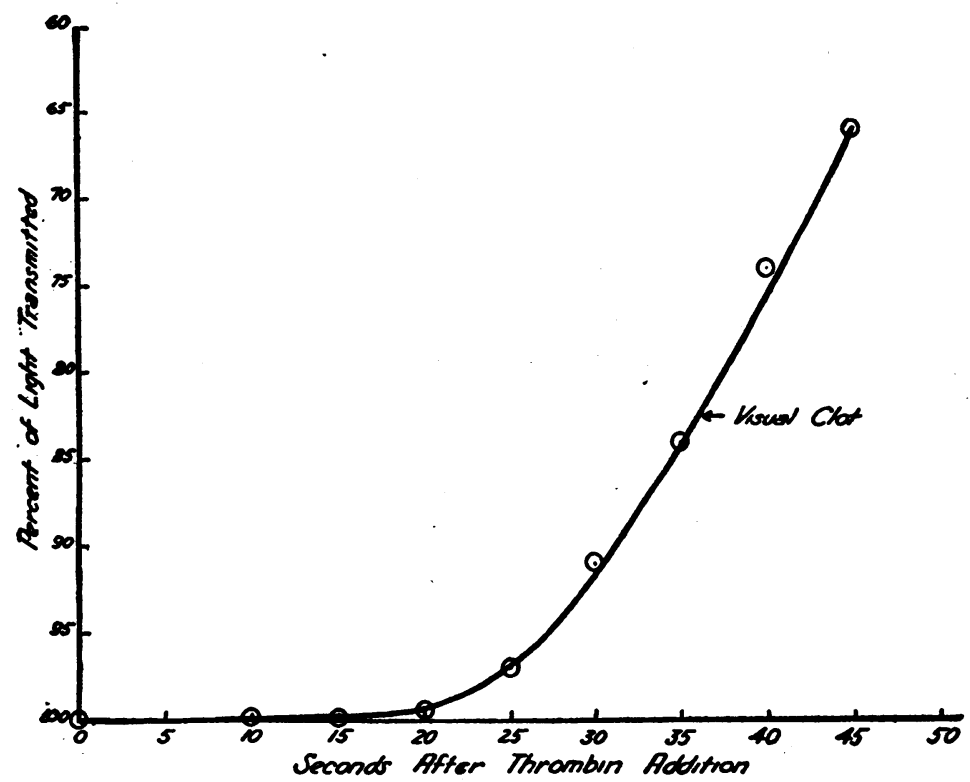

Fig. 1. Light Absorption Curve during Fibrin Formation 0.3 per cent fibrinogen, $\mathrm{pH} 6.2,5000 \AA$, temperature $25^{\circ} \mathrm{C}$.

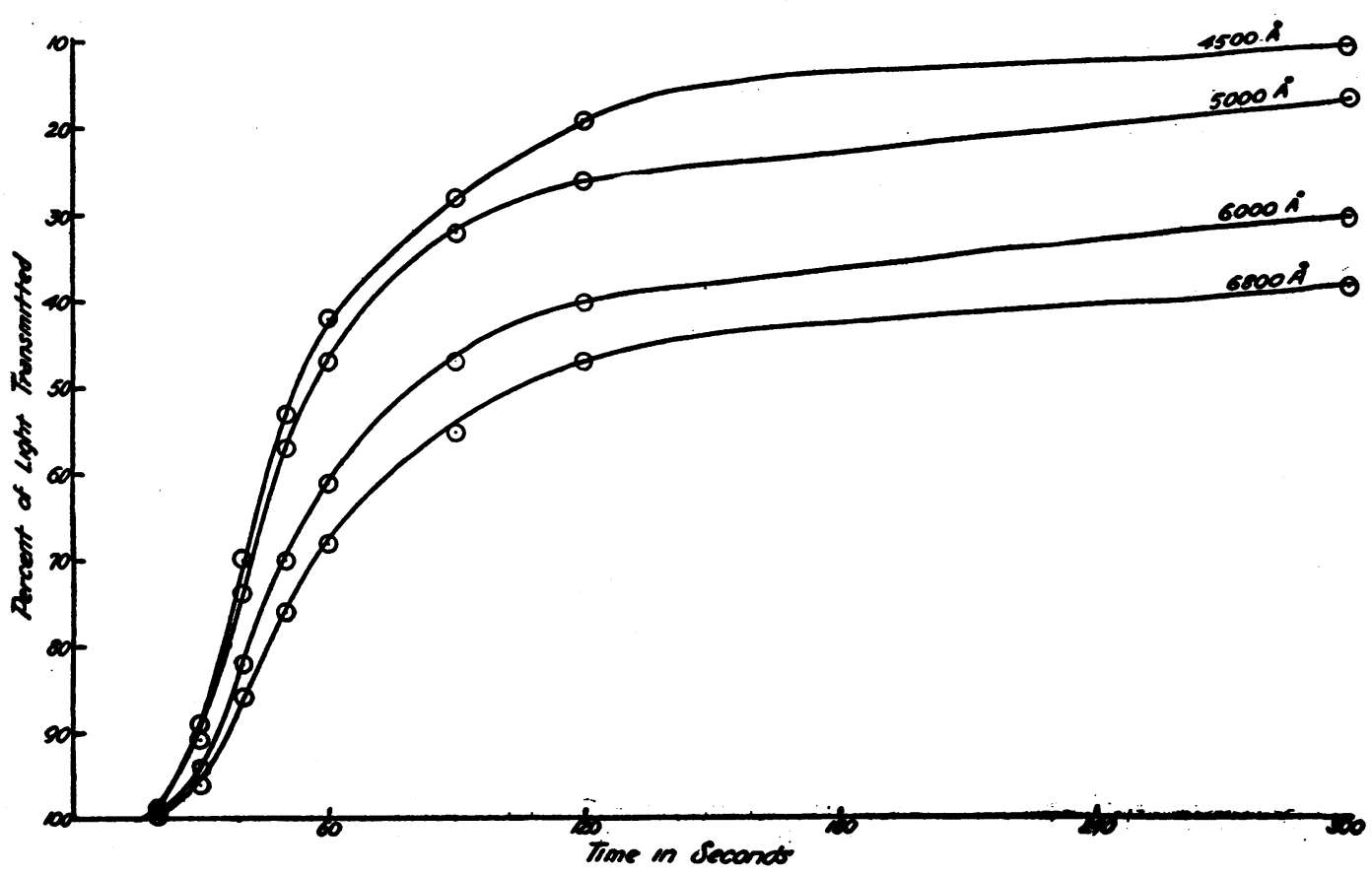

Fig. 2. Liget Absopption as a Function of Wave Length

0.3 per cent fibrinogen, $\mathrm{pH} 6.2$, temperature $25^{\circ} \mathrm{C}$.

3 , this was coincident with an increase in the time needed to form a visible clot. By varying the $\mathrm{pH}$ of the fibrinogen solution and maintaining a constant light source and thrombin additions, it was found that at lower pH values fibrinogen solutions gave greater turbidities when converted to fibrin. At $\mathrm{pH}$ values below 6.0, fibrinogen was found to be relatively unstable, and this range was not investigated. The length of time required to give a 15 per cent increase in light absorption at varying $\mathrm{pH}$ is shown in Figure 4. It is apparent that visual and 


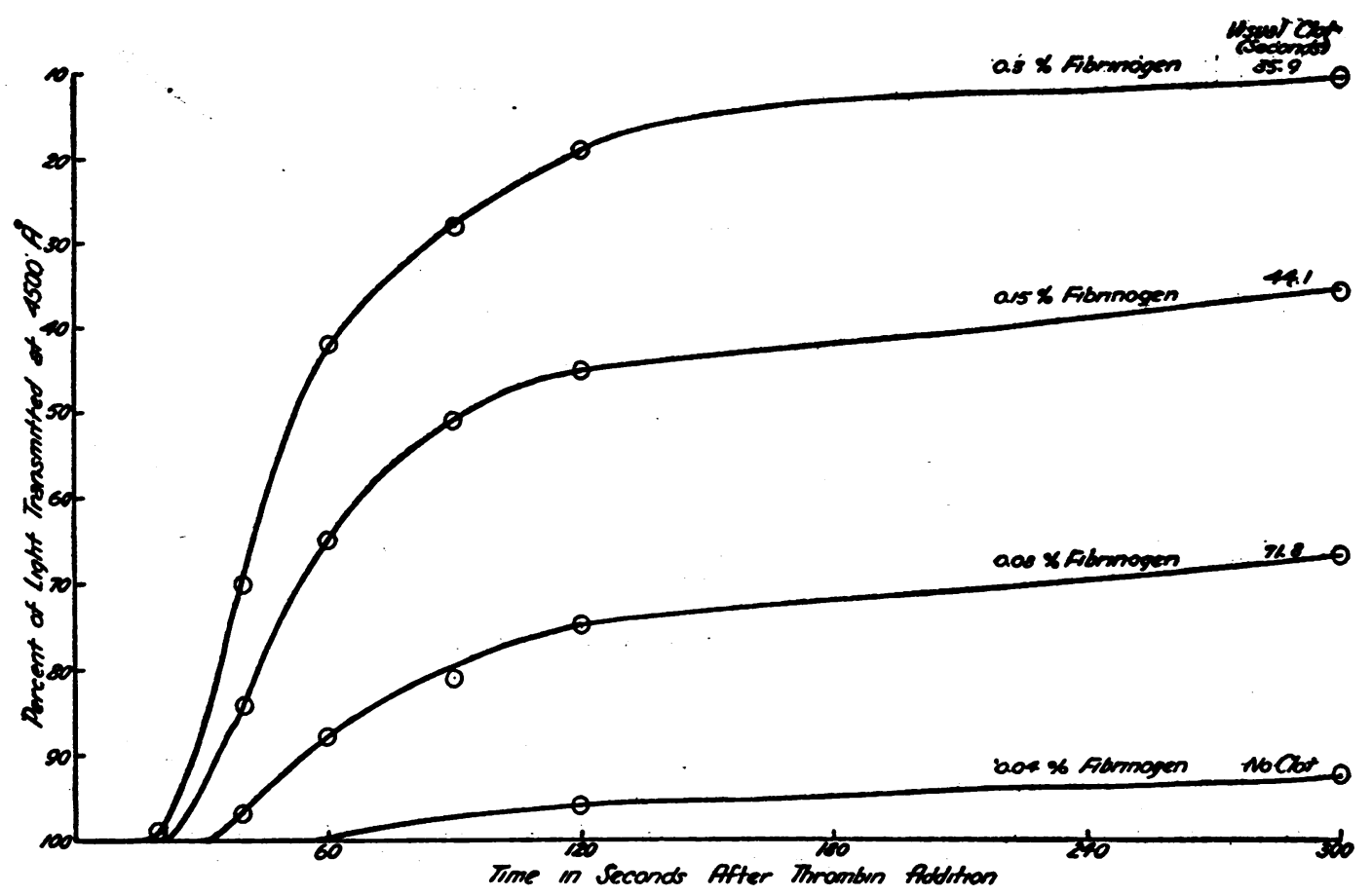

Fig. 3. Light Absorption as a Function of Fibrinogen Concentration $5000 \AA, \mathrm{pH} 6.2$, temperature $25^{\circ} \mathrm{C}$.

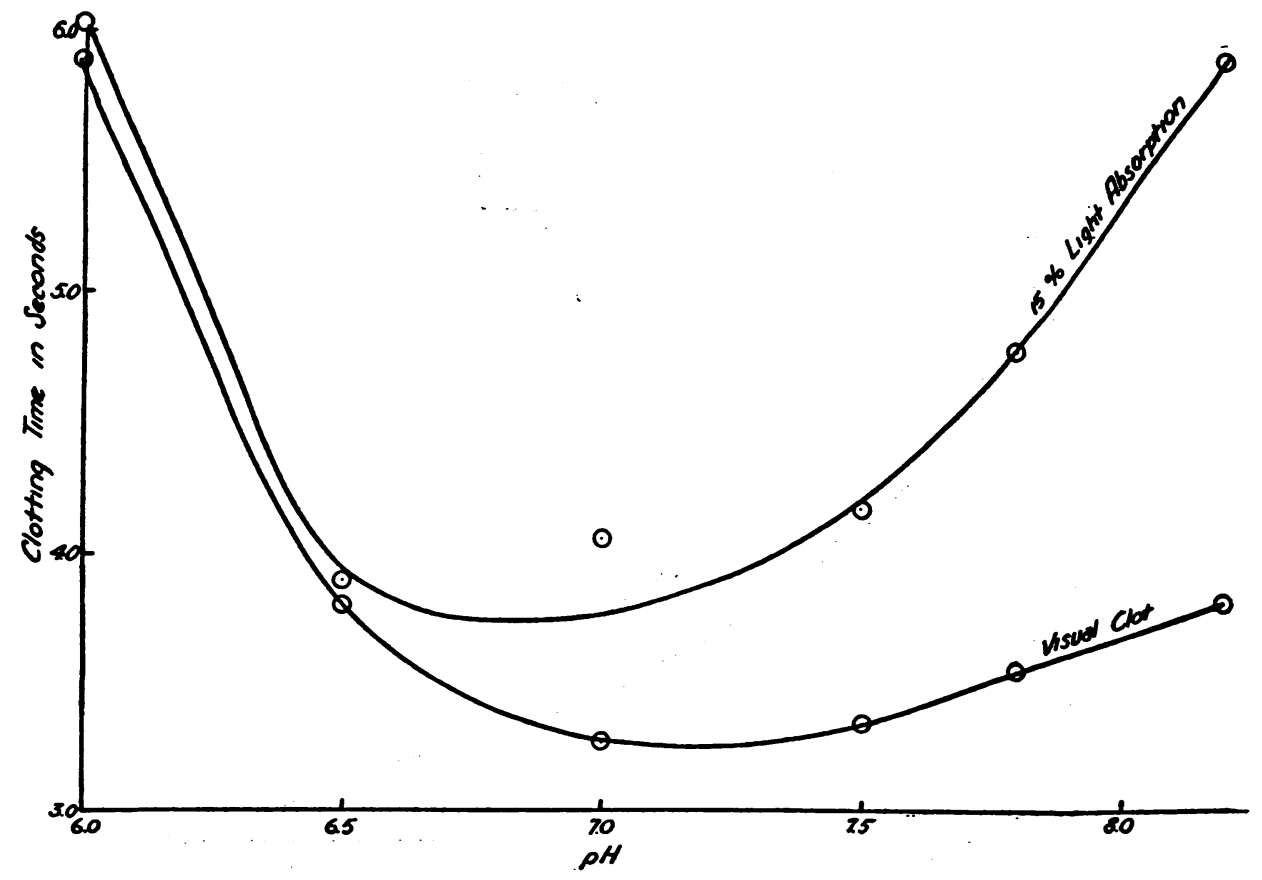

Fig. 4. Efrect of pH on Visual and Photoelectric Clotring Tmas 0.3 per cent fibrinogen, $5200 \AA$, temperature $25^{\circ} \mathrm{C}$. 


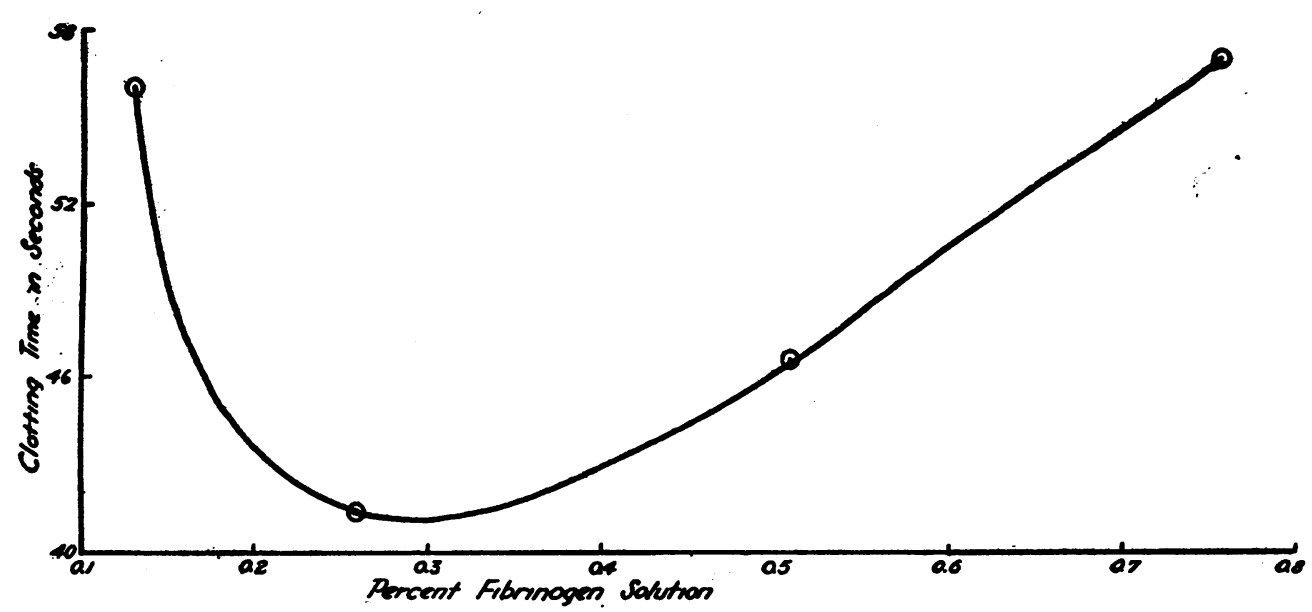

Fig. 5. Clotting Times versus Fibrinogen Concentration

pH 6.2, 5200A, temperature $25^{\circ} \mathrm{C}$.

photoelectric clotting times are relatively parallel from pH 6.0 to 6.5 , but at this point they diverge widely. Another factor which affects the clotting time is the concentration of fibrinogen. It can be seen from Figure 5 that upon varying the fibrinogen level and maintaining a constant $\mathrm{pH}$, the clotting time approached a minimum at about 0.3 per cent fibrinogen.

Experiments of the above nature indicated that clotting times determined visually agreed with the photoelectric measurements based on a 15 per cent increase in light absorption at $5200 \AA$ (galvanometer decrease from 100 to 85 ) when using a 0.3 per cent solution of fibrinogen at pH 6.1 to 6.3. Since the clotting time determined under the above conditions is not a straight line function of the amount of thrombin used (Figure 6), a clotting time in the neighborhood of 45 seconds was used whenever possible, and for the purpose of comparison, all solutions assayed were diluted to give a value close to this figure. Since the photoelectric method showed less variation and was less tedious than visual methods, it was used for all thrombin determinations in which the "two-stage" technique was used.

\section{ASSAY OF FRACTION II + III}

The protein fraction of human plasma precipitated by the low temperature-ethanol fractionation method of Cohn et al. (1), which is designated as Fraction II + III, contains the major portion of the blood prothrombin. It can be further separated into a relatively pure

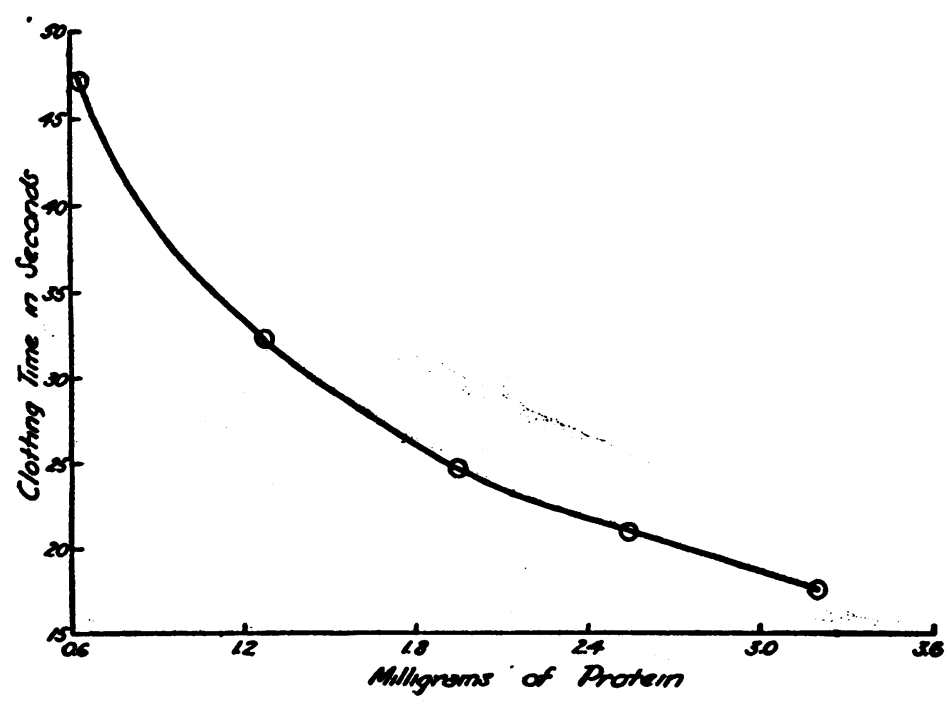

Fig. 6. Clotting Tine versus Thromain Concrestration 0.3 per cent fibrinogen, $\mathrm{pH} 6.2,5200 \mathrm{~A}$, temperature $25^{\circ} \mathrm{C}$. 
$\gamma$-globulin fraction (Fraction II), a fraction (Fraction III-1) in which the isohemoglutinins are concentrated, and a fraction containing the prothrombin (Fraction III-2). In order to study the concentration of prothrombin isolated from Fraction II + III as Fraction III-2 or subfractions thereof, it is necessary to be able to determine the concentration of this entity in the starting material. The assay of this material (Fraction II + III) is complicated by the presence of thrombin inhibitors. After the addition of thromboplastin to a solution of Fraction II + III to convert prothrombin to active thrombin, the latter can be determined by the photoelectric assay which has been described above. However it should be noted that if the activation of prothrombin is carried out at $\mathrm{pH}$ values from 7.0 to 8.0, thrombin values as indicated by variable clotting times are not constant and tend to decrease very markedly. From Figure 7, it is apparent that by carrying out this conversion at $\mathrm{pH} 6.0$, a slower transformation of the prothrombin is effected, but the thrombin content reaches a maximum which tends to remain constant for a period of time suitable for a more reliable assay. Moreover,

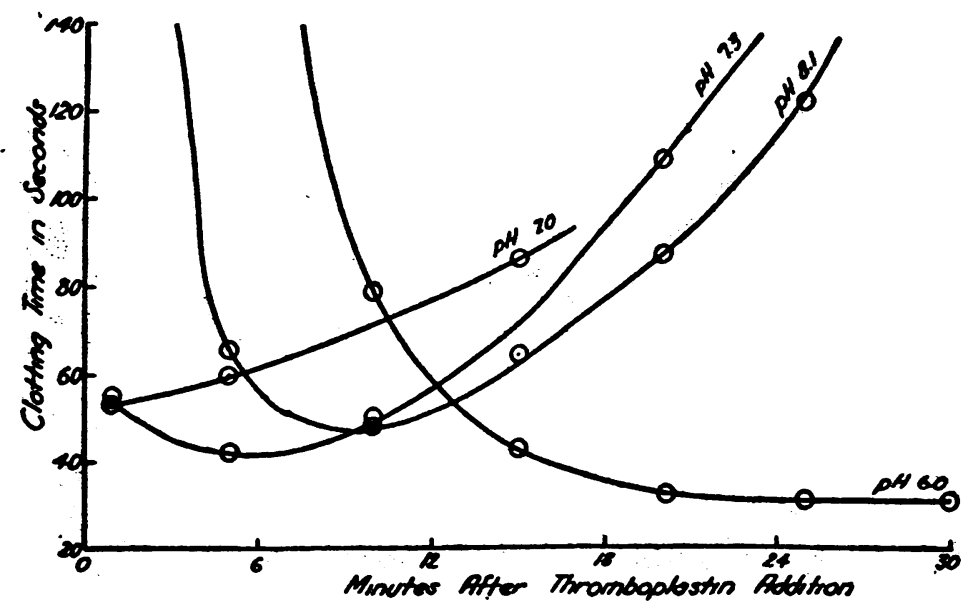

Fig. 7. Activation of Prothrombin in Fraction II + III at Dimfrerent pH's

Thrombin assay at 0.3 per cent fibrinogen, $\mathrm{pH} 6.2,5200 \AA$, temperature $25^{\circ} \mathrm{C}$.

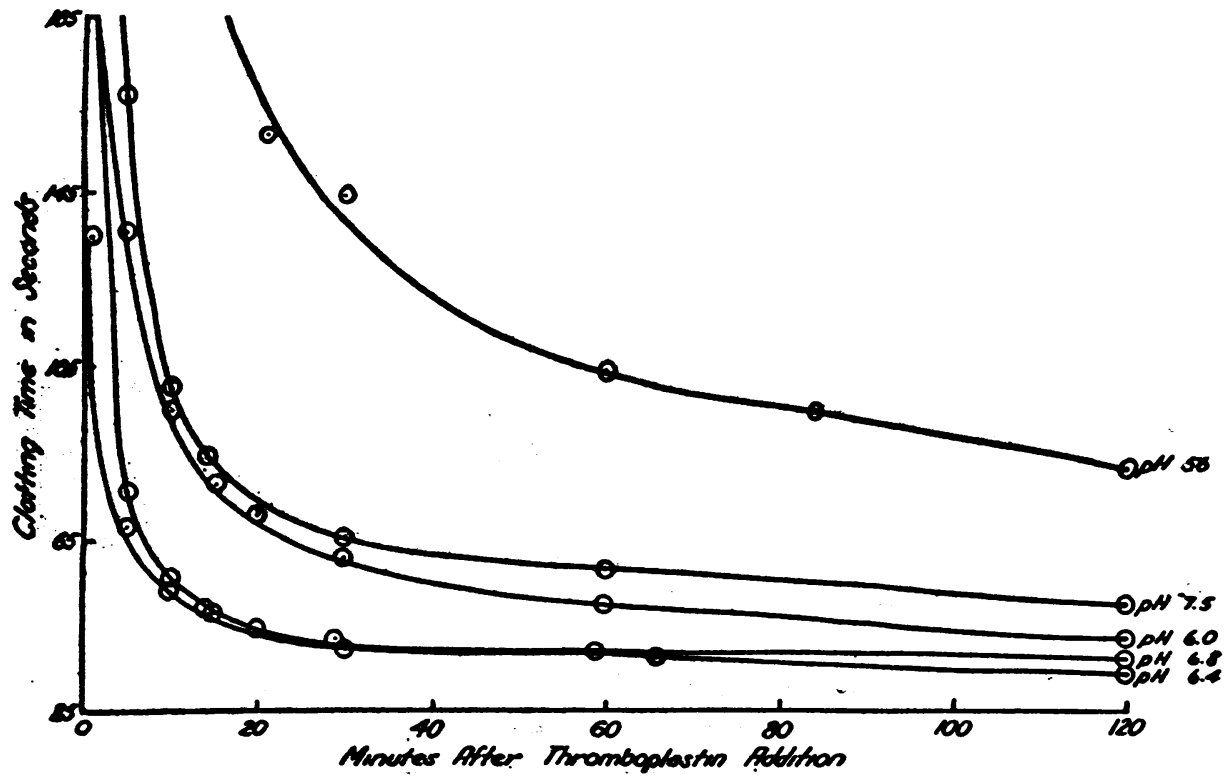

Fig. 8. Activation of Prothrombin in Fraction III-2 at Difterent pH's

Thrombin assay at 0.3 per cent fibrinogen, pH $6.2,5200 \AA$, temperature $25^{\circ} \mathrm{C}$. 


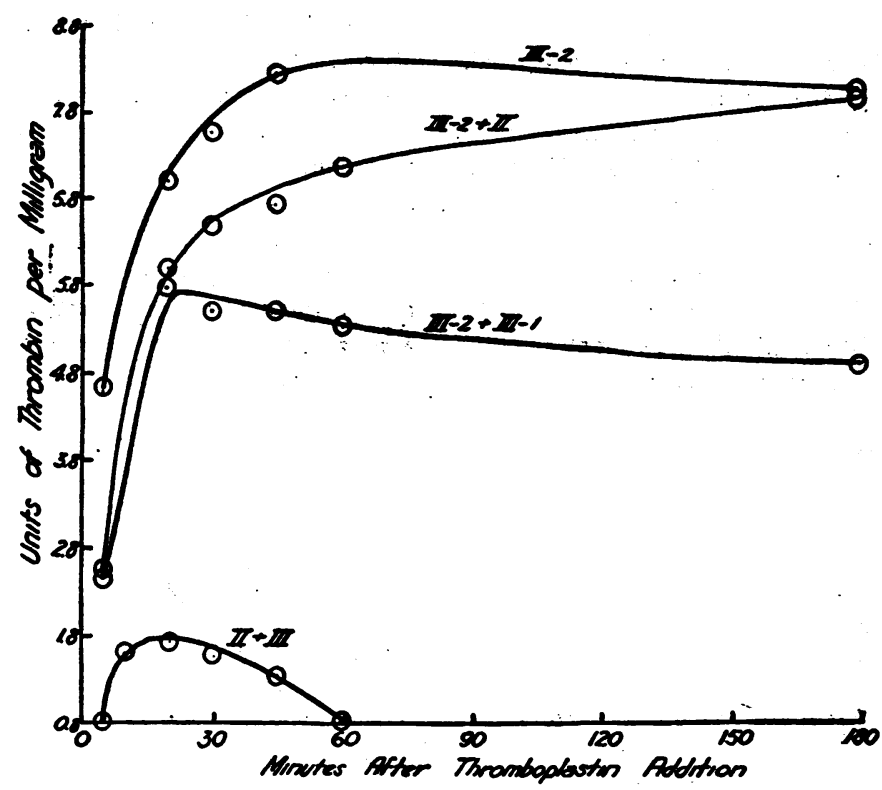

Fig. 9. Emfect of Fractions of II + III on Clotting Times of Fraction III-2

Thrombin assay at 0.3 per cent fibrinogen, $\mathrm{pH} 6.2,5200 \AA$, temperature $25^{\circ} \mathrm{C}$.

under these conditions higher thrombin values are realized.

Fraction III-2, derived from Fraction II + III, while containing the greater portion of the prothrombin, lacks most of the inhibitors present in the parent fraction. However, it can be seen from Figure 8 that not only is the activation of the prothrombin in Fraction III-2 more rapid at $\mathrm{pH}$ values of 6.4 and 6.8 , but there appears to be a greater yield of thrombin as evidenced by shorter clotting times. Since subfraction of II + III yields a prothrombin fraction low or lacking in inhibitors, addition of the other subfractions (II and III-1) to III-2 should influence the clotting time of III-2 if the inhibitors have been separated rather than destroyed. The prothrombin in Fraction II + III and III-2 and in mixtures of III-2 with Fractions II and III-1 was activated at pH 7.0 and then assayed in the usual manner by using equal amounts of II + III and III-2 protein. The Fractions II and III-1 were added to $\mathrm{III}-2$ in amounts sufficient to restore their original II + III ratios. From Figure 9, it can be seen that Fraction II retarded the rate of conversion of prothrombin, while III-1 tended to prevent conversion of a portion of the prothrombin to thrombin and to destroy or inactivate a portion of the thrombin. Since III-1 did not cause the amount of inhibition and destruction that was indicated in Fraction II + III, it appears that partial destruction or loss of these inactivators has taken place in the subfractionation.

It was found impossible to use the photoelectric method for determining the clotting times of plasma or dilutions of plasma by the usual "one stage": method. This method consists in adding a mixture of thromboplastin and $\mathrm{Ca}$ ions to oxalated plasma and noting the time required for the appearance of a clot. The clotting times are too short in the undiluted samples, and the low concentrations of fibrinogen in the higher dilutions does not allow for development of sufficient turbidity. Preliminary experiments indicated that the photoelectric assay would prove satisfactory if the clotting was carried out in the presence of a constant level of fibrinogen and with a plasma dilution sufficient to give a clotting time of $\mathbf{3 0}$ seconds or above.

\section{DISCUSSION}

A thorough discussion of the work on the assay of prothrombin in certain blood fractions prepared by ethyl alcohol precipitation of human plasma would necessarily involve a long review and consideration of the merits and disadvantages of the "two-stage" method of thrombin determination. It suffices to say that this method is quantitative in its approach but suffers from the fact that in certain assay material inhibitors tend to inactivate or destroy a portion of the thrombin or to prevent conversion of prothrombin to thrombin. Highly diluted plasma has been used to minimize the antithrombic activity of plasma before converting the prothrombin to thrombin (2.). However, the 
question of how much thrombin is recovered is a difficult one to evaluate since the conversion of prothrombin to thrombin is being carried out simultaneously with a reaction in which thrombin is being removed by inhibitors. Hence, it is impossible to ascertain the percentage of prothrombin recovered in the low or inhibitor free Fraction III-2 from the inhibitor rich Fraction II +III.

The inhibitors in Fraction II + III appear to be concentrated in the sub-Fraction III-1 although they no longer possess all of the characteristics of the inhibitors present in the parent fraction. Fraction III-1, while preventing maximum conversion of prothrombin to thrombin, did not appear to remove thrombin as readily as was true for Fraction II + III (Figure 9). It is possible that 2 types of inhibitors are present, 1 which inhibits the conversion of prothrombin to thrombin, and another which destroys or inactivates thrombin. The effect of Fraction III-1 on III-2 suggests that the latter type of inhibitor might be lost or destroyed in the fractionation process. The presence of relatively pure $\gamma$-globulin (Fraction II) definitely retarded the rate of conversion of prothrombin but did not affect the final unitage.

The nature of the inhibitors was not investigated. Plasma thrombin inhibitor is believed to reside in the albumin fraction (9 to 11). Recently it has been shown (12) that the anticoagulant of animal tissues accompanies the albumin fraction of tissue extracts and appears to be a lipid. It is not known if the inhibitors in Fractions II + III and III-1 are of such a nature although these materials contain relatively large amounts of lipoprotein and do not lend themselves readily to prothrombin assay.

The conversion of prothrombin to thrombin is likewise somewhat dependent on $\mathrm{pH}$ conditions both for the rate and extent of conversion (Figure 8). However, only a small portion of the protein introduced into these systems is prothrombin, and the results of other workers (13) on the conversion of purified beef prothrombin to thrombin showed that after final equilibration there was complete transformation between $\mathrm{pH} 6.2$ and 8.7 with an optimum rate at $\mathrm{pH}$ 7.2.

These results point to the complexity of accurate thrombin assays on systems containing many poorly understood entities, variations of which tend to markedly affect the final results. Some of the conditions affecting the "two-stage" assay of thrombin have likewise been found to be necessarily closely related to the "one-stage" prothrombin assays. The results of such investigations on the latter system will be presented at a later date.

The assay work in these experiments was rendered less tedious and more reliable by the photoelectric estimation of clot formation. A photoelectric technique has previously been used (5) to study the "one-stage" method of prothrombin assay. We did not find our photoelectric method suitable for this purpose due to the factors mentioned before.

With the isolation and purification of the components concerned with blood clotting, this method might well serve as a more delicate technique for following the associated reactions. In particular, the conversion of fibrinogen to fibrin and possibly the lysis of the latter might lend itself readily to such study. In this connection, the course of the coagulation of fibrinogen by certain organic chemicals could easily be followed (6).

Light scattering of solutions has been shown to be a function of the molecular size of the solute (7), and recently this method has been applied to the study of solutions of high polymers (8). The increase in light scattering of fibrinogen solutions during its conversion to fibrin may possibly be due to a polymerization or condensation of fibrinogen molecules. If such were the case, the above reaction might be investigated by a light scattering technique in which the clotting reactions of dilute fibrinogen solutions are followed in a manner similar to the light absorption studies herein considered.

\section{CONCLUSIONS}

The assay of thrombin in certain human blood protein fractions prepared by ethanol precipitation is difficult and dependent upon $\mathrm{pH}$ conditions which allow for maximum conversion of prothrombin to thrombin.

A photoelectric assay of the clotting time as determined by the "two-stage" method was developed and utilized.

\section{BIBLIOGRAPHY}

1. Cohn, E. J., Oncley, J. L., Strong, L. E., Hughes, W. L., Jr., and Armstrong, S. H., Jr., Chemical, clinical, and immunological studies on the products 
of human plasma fractionation. I. The characterization of the protein fractions of human plasma. J. Clin. Invest., 1944, 23, 417.

2. Warner, E. D., Brinkhous, K. M., and Smith, H. P. A quantitative study of blood clotting : prothrombin fluctuations under experimental conditions. Am. J. Physiol., 1936, 114, 667.

3. Quick, A. J., The nature of the bleeding in jaundice. J. A. M. A., 1938, 110, 1658.

4. Eley, R. C., Green, A. A., and McKhann, C. F., The use of a blood-coagulant extract from the human placenta in the treatment of hemophilia. J. Pediat., 1936, 8, 135.

5. Nygaard, K. K., Hemorrhagic Diseases. C. V. Mosby Co., St. Louis, Missouri, 1941.

6. Chargaff, E., and Bendich, A., On the coagulation of fibrinogen. J. Biol. Chem., 1943, 149, 93.

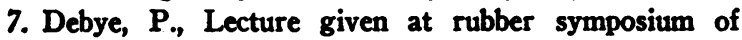
Am. Physical Society, Chicago, Nov. 12, 1943.
8. Doty, P. M., Zimm, B. H., and Mark, H., Some light scattering experiments with high polymer solutions. J. Chem. Physics, 1944, 12, 144.

9. Quick, A. J., The normal antithrombin of the blood and its relation to heparin. Am. J. Physiol., 1938, $123,712$.

10. Wöhlisch, E., and Grüning, W., Uber die antithrombinwirkung der serumproteine und ihre Beziehung zur Metathrombinbildung. Biochem. Ztschr., 1940, $305,183$.

11. Stewart, J. D., and Rourke, G. M., On the inactivation of thrombin by plasma protein. J. Clin. Invest., 1940, 19, 695.

12. Suto-Nagy, de G. J., The chemical nature of an anticoagulant derived from tissues. Proc. Soc. Exp. Biol. and Med., 1944, 57, 284.

13. Loomis, E. C., and Seegers, W. H., Purified prothrombin: factors which influence its activation. Arch. Biochem., 1944, 5, 265. 